American Journal of Infectious Diseases 5 (3): 193-199, 2009

ISSN 1553-6203

(C) 2009 Science Publications

\title{
Standardization of Metal-Based Herbal Medicines
}

\author{
${ }^{1}$ Arun Sudha, ${ }^{2}$ V.S. Murty and ${ }^{1}$ T.S. Chandra \\ ${ }^{1}$ Department of Biotechnology, Indian Institute of Technology Madras, \\ Chennai-600 036, India \\ ${ }^{2}$ Department of Physics, Indian Institute of Technology Madras, Chennai-600 036, India
}

\begin{abstract}
Problem statement: Standardization of herbal drugs is a burning topic in herbal drug industry today. Standardization is difficult because they are usually mixtures of many constituents and the active principle in most cases is unknown. However it is possible to generate a physico-chemical fingerprint for the standardization of these drugs with reference to authentic drugs, for monitoring variation between preparations from different companies and for evaluating batch to batch changes during long term storage. The present study was on the characterization of some of the metal based herbal medicines which were in traditional use for treating infectious diseases. Approach: Modern techniques such as X-Ray Diffraction (XRD), Scanning Electron Microscopy (SEM), Energy Dispersive X-ray Analysis (EDAX), Infrared spectroscopy (IR), Thermogravimetric Analysis (TGA), Inductively Coupled Plasma-Optical Emission Spectroscopy (ICP-OES) and Transmission Electron Microscopy (TEM) were used to generate physico-chemical fingerprint. Results: Our results showed that the metals in most of the herbal medicines were in the oxide or sulfide form. Some of the medicines contained metal particles in the nano range. Conclusion: In order to bring out high quality herbal products, herbal drugs must be standardized using modern techniques.
\end{abstract}

Key words: Bhasmas, chendurams, XRD, EDAX, ICP-OES

\section{INTRODUCTION}

Traditional herbal medicines have been widely used for thousands of years in many countries. Metals have been used in disease treatment since time immemorial. Gold in medicine was mentioned by Roman physician Pliny and Greek philosopher Dioscrides. Hippocrates, the father of modern medicine, explained the beneficial healing and anti-disease properties of silver. In olden days, people used silver bottles for storing water, wine and milk and to prevent spoiling. Siddha medicine is a form of South Indian medicine which is believed to have been developed by the Siddhars, the ancient supernatural spiritual saints of India. In siddha medicines, apart from gold and silver, mercury, sulphur, mica, arsenic, zinc and several other minerals, gems, shells, horns are treated with indigenous herbs and are given as bhasmas and chendurams. A bhasma means a fine ash obtained though incineration. Chendurams are prepared by the process of sublimation and they are much more potent than bhasmas. Siddha medicine has immense faith in the miracles of mercurial drugs and in the prolongation of life through rejuvenating treatments and intense yogic practices ${ }^{[1]}$. Silver, gold, zinc, copper and other metals which are well known to have anti-microbial effect in modern medicines have been used as wonderful life saving drugs against infectious diseases for thousands of years without any adverse effects. Role of these herbo-mineral preparations for curing skin diseases such as psoriasis, eczema, alopecia, diabetic ulcer, warts, vitiligo and leprosy are well studied ${ }^{[2]}$. Most of the medicines are mixture of compounds and because of its synergistic action, toxicity is being diminished, thereby increasing bioavailability through the cells of the body. Treating the minerals with herbal juices may lead to reduction (trituration) in particulate size even up to nano levels (less than $100 \mathrm{~nm}$ ) enabling increased potency. These drugs are known to be effective even in low concentration.

Various commercially available medicines such as Linga Chenduram, Poorna Chandrodaya Chenduram, Kshaya Kulanthaga Chenduram, Velli Parpam, Naga Chenduram and Naga Parpam which contain noble and other metals were used for analysis. These medicines are particularly used for treating infectious diseases. So far, nothing is known about the chemical composition of these medicines and the scientific basis of its application

Corresponding Author: Arun Sudha, Indian Institute of Technology Madras, Chennai- 600 036, India Tel : +91-44-22574103 Fax: +91-44-22574102 
in treating infectious diseases. Proper standardisation techniques for checking the quality are inadequate on these medicines to meet the criteria to support its use worldwide. The aim of our present study is to:

- Analyze the different brands of medicines (bhasmas or powder forms) using several modern analytical techniques to help in quality control and standardization of the drugs

- Collating the data from multiple approaches to suggest the likely speciation of metals present in these complex powders and their bio-absorption potential

- To assess the content and likely potency of very expensive preparations based on noble and other metals

\section{MATERIALS AND METHODS}

Siddha medicines like Poorna Chandrodaya Chenduram (PCC), Kshaya Kulanthaga Chenduram (KsKc), Velli Parpam (SP), Naga Chenduram (NC), Naga Parpam (NP) and three different popular brands of Linga Chenduram (LC1, LC2 and LC3) were procured from government and private market. These commercially available formulations are used for treating various diseases in traditional clinical practice in India and are usually prepared from purified metal, triturated with decoction of herbal juices. They are generally prescribed in the dose of $100-200 \mathrm{mg} \mathrm{day}^{-1}$ and recommended to be taken with a suitable adjuvant.

Perkin-Elmer 5300 DV ICP-OES was used for the determination of elements. About 0.1-0.2 $\mathrm{g}$ of the sample was digested using $\mathrm{HNO}_{3}$ : Perchloric acid (2:1). After the digestion was complete, the flask was allowed to cool and the contents were transferred to a beaker and heated to remove all the acid. The resulting solution was diluted to $50 \mathrm{~mL}$ with deionized water. Perchloric acid was used because it does not form complexes with metals and metalloids ${ }^{[3]}$.
The powder XRD patterns of the solid samples were recorded on X'pert pro analytical X-ray diffractometer using $\mathrm{CuK} \alpha$ radiation filtered by a nickel foil over the range of diffraction angle $10-70^{\circ}$. The wave length of the radiation used was $1.5405 \mathrm{~A}^{\circ}$.

The elemental composition of the samples was determined by JEOL ASM 3500 SEM with EDAX. A representative portion of each sample was sprinkled onto a double side carbon tape and mounted on aluminium stubs, in order to get a higher quality secondary electron image for SEM and EDAX examination.

IR spectra in the region $\left(4000-450 \mathrm{~cm}^{-1}\right)$ were recorded on Perkin-Elmer FTIR Spectrophotometer in $\mathrm{KBr}$ pellets. Thermograms were recorded in air atmosphere on a NETZSCH simultaneous thermoanalyzer.

The presence of nanoparticles was tested by Dynamic Light Scattering (DLS) method using Brookhaven 90 plus particle size analyzer, after suspending the materials in aqueous dispersing phase and filtering through $0.45 \mu$ membrane filter. TEM was used to confirm the presence of nanoparticles.

\section{RESULTS}

ICP-OES analysis: The different samples show variation in metal content (Table 1 ). $\mathrm{Hg}$ is the main component in all brands of LC. There is a wide variation in content of different elements such as As, $\mathrm{Ca}, \mathrm{Cd}, \mathrm{Cr}, \mathrm{Cu}, \mathrm{Fe}$ and $\mathrm{Mg}$ between the three different brands LC1, LC2 and LC3 from three different companies. This could be due to the difference in the amount of plant juices added during preparation by different manufacturers. But these elements constitute only less than $1 \%$ of the samples. PCC contains $\mathrm{Hg}$ as the main constituent and $0.8 \mathrm{mg} \mathrm{g}^{-1}$ of the noble metal gold. KsKc showed the presence of many elements, particularly $\mathrm{Ca}, \mathrm{Fe}, \mathrm{Mg}$ and $\mathrm{As}$ in higher levels, $7.524 \mathrm{mg} \mathrm{g}^{-1}$ gold and $\mathrm{Hg}$ was absent. SP contains $\mathrm{Ag}$ in large amount and also $\mathrm{Ca}$. NC and NP contain large quantities of $\mathrm{Zn}, \mathrm{Ca}$ and $\mathrm{Mg}$.

Table 1: ICP-OES analysis of metal based medicines

\begin{tabular}{|c|c|c|c|c|c|c|c|c|}
\hline Element & $\mathrm{LC} 1\left(\mathrm{mg} \mathrm{g}^{-1}\right.$ & $\mathrm{LC} 2\left(\mathrm{mg} \mathrm{g}^{-1}\right)$ & LC3 $\left(\mathrm{mg} \mathrm{g}^{-1}\right)$ & $\mathrm{PCC}\left(\mathrm{mg} \mathrm{g}^{-1}\right)$ & $\mathrm{KsKc}\left(\mathrm{mg} \mathrm{g}^{-1}\right)$ & $\mathrm{SP}\left(\mathrm{mg} \mathrm{g}^{-1}\right)$ & $\mathrm{NC}\left(\mathrm{mg} \mathrm{g}^{-1}\right)$ & $\mathrm{NP}\left(\mathrm{mg} \mathrm{g}^{-1}\right)$ \\
\hline $\mathrm{Ag}$ & 1.340 & 0.002 & 0.002 & 0.1790 & 0.1312 & 325.5000 & 0.00397 & 0.00926 \\
\hline $\mathrm{Al}$ & BDL & 0.584 & 0.820 & 0.8449 & 7.4592 & BDL & 2.84800 & 3.10100 \\
\hline As & 4.730 & 2.770 & 4.360 & 2.0920 & 32.4640 & 0.0195 & 0.06230 & 0.02500 \\
\hline $\mathrm{Ca}$ & 0.480 & 1.551 & 1.590 & 12.5690 & 117.9680 & 98.0530 & 35.81400 & 39.74500 \\
\hline $\mathrm{Cd}$ & 0.100 & 0.070 & 1.100 & 0.0546 & 0.8496 & $\mathrm{BDL}$ & 0.00390 & 0.00390 \\
\hline $\mathrm{Cr}$ & 0.230 & 0.010 & 0.010 & 0.0377 & 0.0481 & 0.0310 & 0.01120 & 0.00390 \\
\hline $\mathrm{Cu}$ & 0.120 & 0.006 & - & 0.0286 & 0.2672 & 0.2530 & 0.15510 & 0.04960 \\
\hline $\mathrm{Fe}$ & 0.180 & 0.250 & 0.680 & 1.8250 & 117.5680 & 1.4800 & 4.38370 & 4.28300 \\
\hline $\mathrm{Mg}$ & 0.030 & 0.230 & 0.270 & 0.5038 & 47.5680 & 2.2120 & 10.47600 & 15.50210 \\
\hline $\mathrm{Mn}$ & BDL & 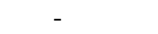 & 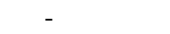 & 0.0208 & 0.5680 & 0.0338 & 0.19290 & 0.27340 \\
\hline $\mathrm{Ni}$ & 0.006 & - & - & 0.0090 & 0.2256 & 0.0130 & 0.01320 & 0.02380 \\
\hline $\mathrm{Pb}$ & 0.009 & 0.030 & 0.010 & 0.0830 & 0.0320 & 0.0351 & 1.67760 & 0.10130 \\
\hline $\mathrm{Zn}$ & 0.105 & 0.110 & 0.140 & 0.2290 & 0.5040 & 0.1575 & 388.90000 & 388.38000 \\
\hline $\mathrm{Hg}$ & 374.800 & 412.300 & 488.100 & 143.7400 & $\mathrm{BDL}$ & 1.3220 & 4.24100 & $\mathrm{BDL}$ \\
\hline $\mathrm{Au}$ & . & 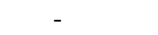 & - & 0.8000 & 7.5240 & - & - & - \\
\hline
\end{tabular}

BDL: Below detectable limit; LC1, LC2 and LC3: Brand 1, Brand 2 and Brand 3 of Linga Chenduram: PCC: Poorna chandrodaya chenduram, kskc- kshaya kulanthaga chenduram, SP: Velli Parpam, NC : Naga Chenduram, NP: Naga Parpam 


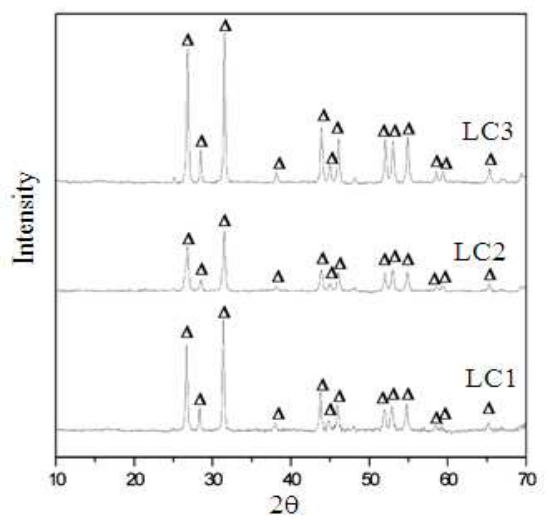

Fig. 1: XRD pattern of Linga Chendurams; LC1, LC2 and LC3: Brand 1, 2 and 3 of Linga Chenduram; $\Delta: \mathrm{HgS}$

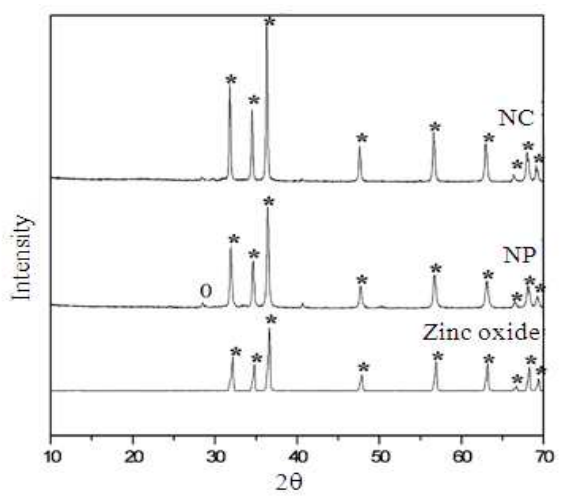

Fig. 2: XRD pattern of standard $\mathrm{ZnO}$ and zinc based medicines; NC: Naga Chenduram; NP: Naga Parpam; *: ZnO 0: Unknown

XRD: The XRD patterns of the metal based herbal medicines are shown in Fig. 1-3. XRD scans of three different brands of LC (Fig. 1) are found to be similar (showed main peaks near 31.5 and $26.7^{\circ}$ ) and correspond to the standard peaks for $\mathrm{HgS}$. NC and NP showed main peaks near 36.3 and $31.8^{\circ}$, which correspond to XRD pattern of standard $\mathrm{ZnO}$ (Fig. 2). XRD pattern of PCC coincide well with the standard peaks of $\mathrm{HgS}$. KsKc showed the presence of many elements. The peak at $35.52^{\circ}$ is due to $\mathrm{Fe}_{3} \mathrm{O}_{4}$. The form of gold, arsenic and silver in PCC, KsKc and SP could not be identified using XRD pattern (Fig. 3).

SEM and EDAX analysis: SEM images of LC1, PCC, $\mathrm{KsKc}$ and SP showed difference in size and agglomeration of the particles (Fig. 4a-d). Agglomeration of the particles is due to repeated cycles of calcinations involved in preparation ${ }^{[4]}$. The elemental composition of the drug samples were analyzed by EDAX (Table 2).

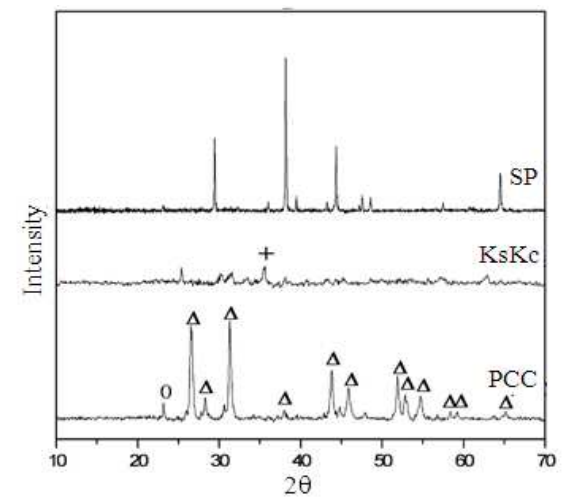

Fig. 3: XRD pattern of Gold and Silver based medicines; PCC: Poorna Chandrodaya Chenduram; KsKc: Kshaya Kulanthaga Chenduram; SP: Velli Parpam; $\Delta$ : $\mathrm{HgS}, 0$ : Unknown, +: $\mathrm{Fe}_{3} \mathrm{O}_{4}$

Table 2: EDAX analysis of metal based medicines

\begin{tabular}{|c|c|c|c|c|c|c|c|c|}
\hline \multirow{2}{*}{$\begin{array}{l}\text { Elements } \\
\text { present }\end{array}$} & \multicolumn{2}{|l|}{ LC1 } & \multicolumn{2}{|l|}{ PCC } & \multicolumn{2}{|l|}{ KsKc } & \multicolumn{2}{|l|}{ SP } \\
\hline & wt (\%) & At $(\%)$ & wt (\%) & At (\%) & wt (\%) & At (\%) & wt (\%) & At $(\%)$ \\
\hline $\mathrm{Hg}$ & 79.89 & 38.59 & 30.27 & 5.59 & 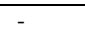 & - & - & - \\
\hline & 18.58 & 56.15 & 53.55 & 61.88 & 3.40 & 2.76 & - & - \\
\hline U & - & - & 11.86 & 27.48 & 34.32 & 55.94 & 30.26 & 46.49 \\
\hline $\mathrm{Na}$ & - & - & 2.41 & 3.88 & 2.18 & 2.47 & - & - \\
\hline $\mathrm{Si}$ & 1.53 & 5.26 & - & - & 11.13 & 10.33 & 0.86 & 0.75 \\
\hline 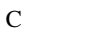 & - & - & - & - & - & - & 15.03 & 30.75 \\
\hline $\mathrm{Al}$ & - & - & - & 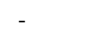 & 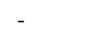 & - & 0.52 & 0.48 \\
\hline $\mathrm{Ca}$ & - & - & 1.10 & 1.02 & 12.35 & 8.04 & 21.76 & 13.35 \\
\hline $\mathrm{Au}$ & - & - & 0.81 & 0.15 & 0.94 & 0.12 & 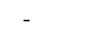 & \\
\hline $\mathrm{Mg}$ & - & - & - & - & 10.16 & 10.90 & 1.26 & 1.2 \\
\hline $\mathrm{Ag}$ & - & - & - & - & & & 30.31 & 6.91 \\
\hline $\mathrm{Cl}$ & - & - & 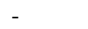 & - & 3.19 & 2.34 & - & - \\
\hline K & - & - & - & - & 0.69 & 0.46 & - & - \\
\hline $\mathrm{Ba}$ & - & - & - & - & 0.25 & 0.05 & - & - \\
\hline $\mathrm{Fe}$ & - & - & - & - & 11.04 & 5.16 & - & - \\
\hline $\mathrm{Cu}$ & 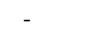 & - & - & - & 0.45 & 0.18 & - & - \\
\hline $\mathrm{Pb}$ & - & - & - & - & 9.90 & 1.25 & - & - \\
\hline
\end{tabular}

LC1: Brand 1 of Linga Chenduram; PCC: Poorna chandrodaya chenduram; KsKc: Kshaya kulanthaga chenduram; SP: Velli parpam

From this analysis, it was confirmed that $79.89 \% \mathrm{Hg}$ present in $\mathrm{LC} 1$ is equivalent to $92.63 \% \mathrm{HgS}$ (as per the stoichiometry) while, other elements are $\mathrm{S}$ and $\mathrm{Si}$. In $\mathrm{PCC}, \mathrm{HgS}$ is the main component and a small percentage of $\mathrm{Hg}$ may also occur in oxide form. KsKc shows the presence of many elements, so the exact form could not be concluded. This is in correlation with ICPOES and XRD data. PCC and KsKc contain small percentage of gold. SP showed higher levels of $\mathrm{Ag}, \mathrm{Ca}$ and $\mathrm{O}_{2}$. So, the most probable forms may be silver oxide and calcium oxide. SEM and EDAX provide good estimate of the concentration of main elements in the sample in a significantly faster way compared to ICP-OES method. Furthermore, it provides useful information on the distribution of the element forming the sample and their possible chemical form ${ }^{[5]}$. 


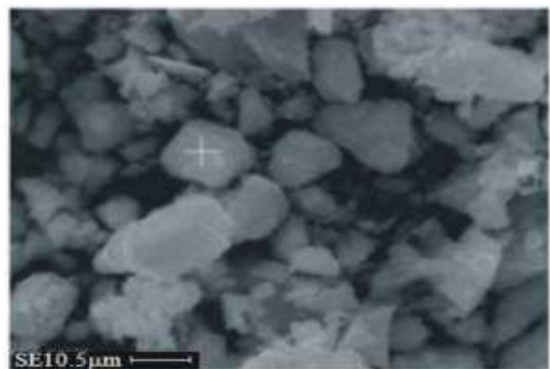

(a)

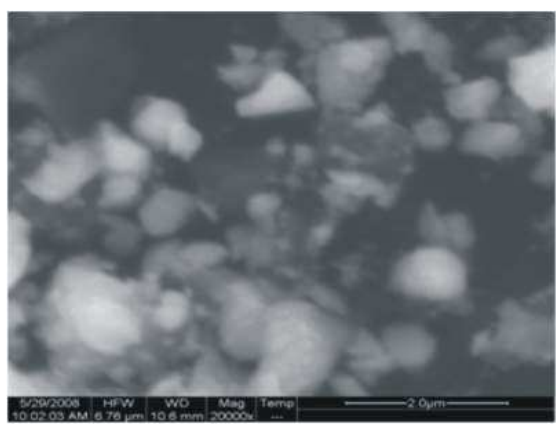

(b)

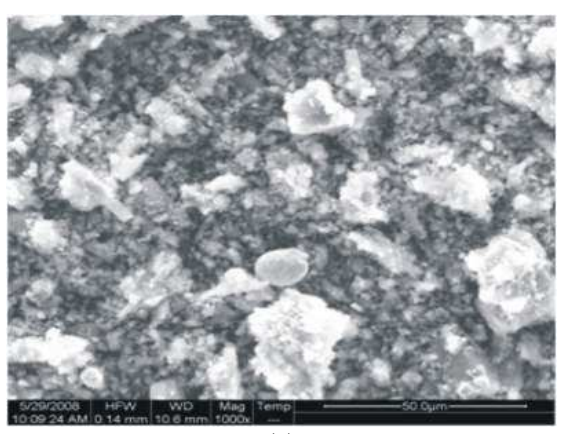

(c)

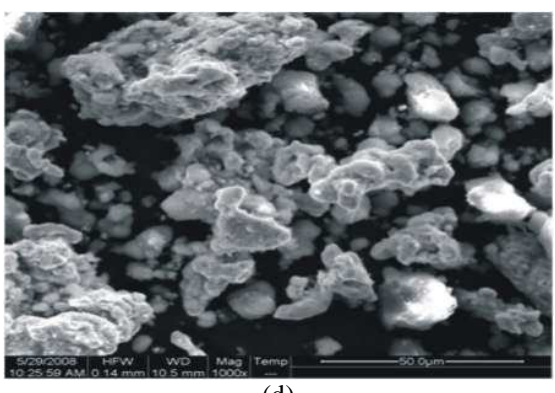

(d)

Fig. 4: (a): SEM of LC1; (4b): PCC; (4c): KsKc; (4d): SP

FTIR: FT-IR spectra of the drug samples show that they do not contain organic compounds (Fig. 5-7). The absence of organic matter is further proof of proper incineration during the preparation of these medicines

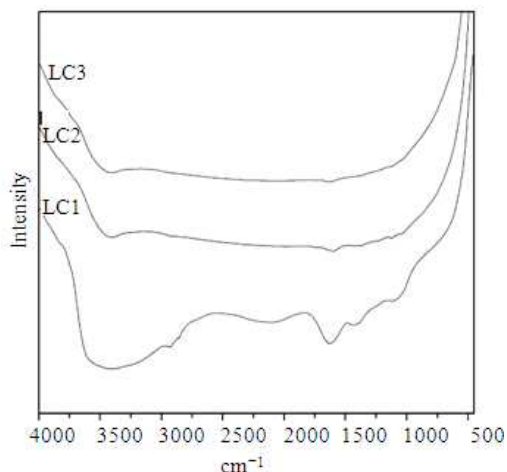

Fig. 5: FT-IR of Linga Chendurams; LC1, LC2 and LC3: Brand 1, 2 and 3 of Linga Chenduram

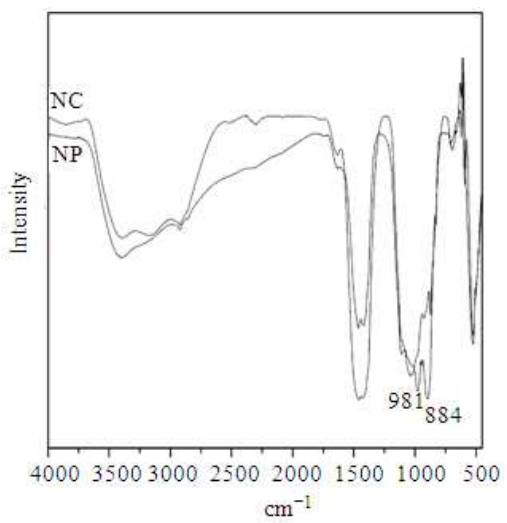

Fig. 6: FT-IR of Zinc based medicines; NC: Naga Chenduram; NP: Naga Parpam

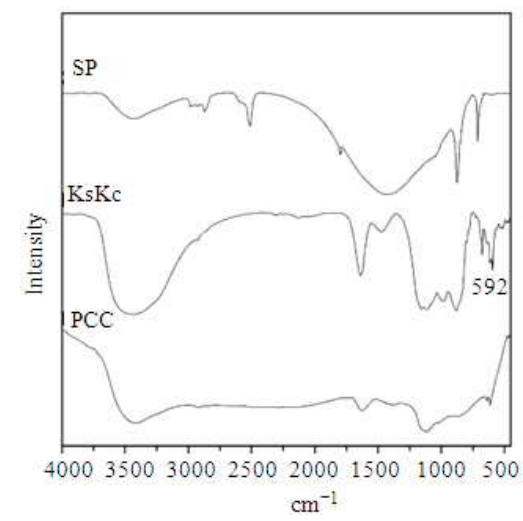

Fig. 7: FT-IR of Gold and Silver based medicines; PCC: Poorna Chandrodaya Chenduram, KsKcKshaya Kulanthaga Chenduram; SP: Velli Parpam

and the absence of any external organic contamination. This is in agreement with the earlier infrared study of Bhasmas ${ }^{[6]}$. The three different brands of LC showed a 
Am. J. Infect. Dis., 5 (3): 193-199, 2009

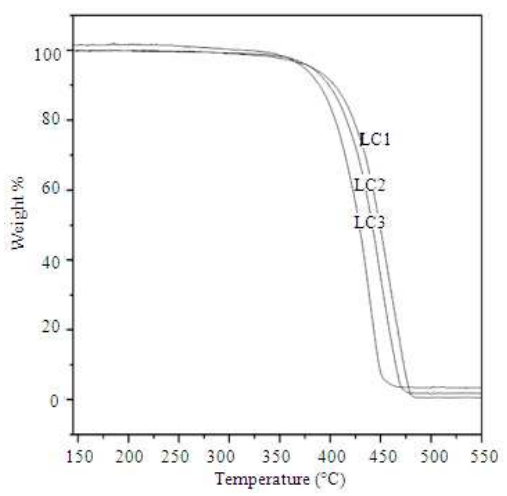

Fig. 8: Thermogravimetric Analysis of Linga Chendurams; LC1, LC2 and LC3: Brand 1, 2 and 3 of Linga Chenduram

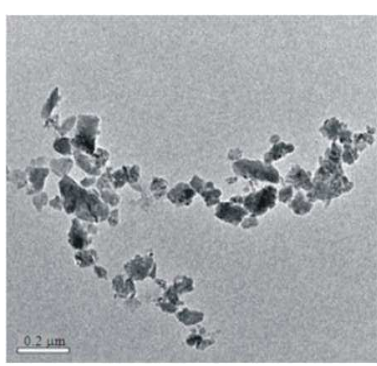

(a)

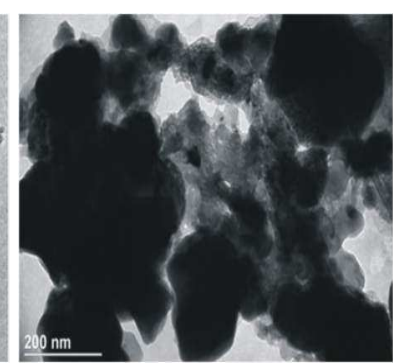

(b)
Fig. 9: (a): TEM of LC1; (b): PCC

similar pattern and it can be used as a chemical fingerprint (Fig 5). IR Spectrum of PCC is similar to Linga Chenduram. The peak at $592 \mathrm{~cm}^{-1}$ in KsKc is due to $\mathrm{Fe}_{3} \mathrm{O}_{4}{ }^{[7]}$. The exact form of silver in SP could not be concluded using IR Spectrum (Fig. 7). The broad peaks at 3400 and $1600 \mathrm{~cm}^{-1}$ in all the samples are due to the characteristic $\mathrm{OH}$ stretching $(\gamma-\mathrm{OH}) \mathrm{H} \mathrm{OH}$ bending $(\delta$ $\mathrm{OH})$ vibrational bands due to adsorbed water in the sample ${ }^{[8]}$.

TGA: TGA curves for three brands of LC are shown in Fig. 8. When all the three brands of LC are heated in the presence of air, it showed complete decomposition at $500^{\circ} \mathrm{C}$ itself. Hardy et al. ${ }^{[9]}$ report that if $\mathrm{HgS}$ is heated in air it is first converted to mercuric oxide and then decomposes to mercury vapour and oxygen at about $500^{\circ} \mathrm{C}$. Since the TGA curves show the complete decomposition at $500^{\circ} \mathrm{C}$, it confirms the presence of mercuric sulphide. The presence of only $\mathrm{HgS}$ in $\mathrm{LC}$ is also confirmed by XRD data.

DLS: Ancient literatures regarding the preparation of Bhasmas give importance to particle size.
Table 3: Particle size analysis of metal based medicines by dynamic light scattering

\begin{tabular}{|c|c|c|c|c|c|c|c|c|}
\hline \multirow{2}{*}{$\begin{array}{l}\text { Percentage } \\
\text { of particles }\end{array}$} & \multicolumn{8}{|c|}{ Particle size less than in $(\mathrm{nm})$} \\
\hline & LC1 & LC2 & $\mathrm{LC} 3$ & PCC & $\mathrm{KsKc}$ & SP & $\mathrm{NC}$ & NP \\
\hline 10 & 88.8 & 90.8 & 69.2 & 139.9 & 397.1 & 188.7 & 357.8 & 233.9 \\
\hline 20 & 107.1 & 105.2 & 82.1 & 174.7 & 521.3 & 232.1 & 452.8 & 305.3 \\
\hline 30 & 122.6 & 117.1 & 92.9 & 205.1 & 643.7 & 269.6 & 536.7 & 370.0 \\
\hline 40 & 137.6 & 128.2 & 103.2 & 235.2 & 750.5 & 306.2 & 620.4 & 435.9 \\
\hline 50 & 153.3 & 139.5 & 113.9 & 267.2 & 877.7 & 344.9 & 710.3 & 508.0 \\
\hline 60 & 170.7 & 151.9 & 125.6 & 303.6 & 1026.5 & 388.5 & 813.2 & 592.1 \\
\hline 70 & 191.6 & 166.3 & 139.5 & 348.1 & 1213.0 & 441.3 & 940.0 & 697.5 \\
\hline 80 & 219.4 & 185.0 & 157.9 & 408.7 & 1477.7 & 512.5 & 1114.2 & 845.5 \\
\hline 90 & 264.6 & 214.4 & 187.3 & 510.4 & 1625.0 & 630.4 & 1409.7 & 1103.3 \\
\hline 95 & 308.8 & 242.1 & 215.6 & 613.0 & 2428.9 & 747.7 & 1711.8 & 1374.2 \\
\hline
\end{tabular}

LC1, LC2 and LC3: Brand 1, Brand 2 and Brand 3 of Linga Chenduram; PCC: Poorna Chandrodaya Chenduram, KsKc: Kshaya Kulanthaga Chenduram, SP: Velli Parpam, NC: Naga Chenduram, NP: Naga Parpam

It is mentioned in the texts that the process of Marana (incineration) should be repeated to get the smaller particle size. All the medicines were screened for nanoparticles (Table 3). LCs alone show narrow range of distribution of particles. Brand 3 of LC had 10\% of the particles below $69.2 \mathrm{~nm}$. PCC had particle size close to nano. It is surprising that thousands of years old Indian system of medicine had knowledge of nanoscience, which modern science has just started exploring in the 21 st century.

TEM analysis: The medicines LC1 and PCC which showed particles in the nano or near nano range were further analyzed using TEM (Fig. 9a-b). TEM Pictures show that particles are not of uniform size. There is more number of particles in the range of $40-50 \mathrm{~nm}$ in LC and the particles in PCC are slightly larger. In both $\mathrm{LC} 1$ and PCC, the presence of $\mathrm{HgS}$ in the nanoparticles was also confirmed by EDAX attached with TEM. So far there appears to be no reference for $\mathrm{HgS}$ in nanoform being used in traditional medicines.

\section{DISCUSSION}

LC is used to treat fevers, skin diseases and also venereal diseases. It is given along with honey in the dose of 50-100 mg day ${ }^{-1}$. Particle size analysis by DLS and TEM showed the presence of nanoparticles (below $100 \mathrm{~nm}$ ). This may enhance bioabsorption and efficacy. EDAX, XRD and TGA confirmed the presence of $\mathrm{HgS}$ as the main constituent. $\mathrm{HgS}$ is less toxic and less absorbed than other forms of mercury such as elemental mercury and organic mercury. Jiunn-Jye Chuu et al. ${ }^{[10]}$ report that the low dosage of $\mathrm{HgS}\left(0.1 \mathrm{~g} \mathrm{~kg}^{-1} \mathrm{day}^{-1}\right)$ for 7 consecutive days did not produce any toxic effects in experimental mice. The toxic effect of $\mathrm{HgS}$ (even $1.0 \mathrm{~g} \mathrm{~kg}^{-1}$ ) disappeared completely in 5 weeks 
subsequent to the cessation of its administration. But, methyl mercury $\left(2.0 \mathrm{mg} \mathrm{kg}^{-1} \mathrm{day}^{-1}\right)$ persisted at least 11 weeks subsequent to the cessation of its administration $^{[10]}$. Long term use of $\mathrm{HgS}$ may lead to the accumulation of mercury in liver and kidneys. The correct preparation methods, appropriate dosage, disease condition, age and drug combinations greatly influence $\mathrm{HgS}$ toxicity. Three brands of LC showed a similar pattern in XRD, FTIR and TGA and indicate that these techniques can be used as rapid physicochemical fingerprints for quality control of these medicines.

PCC is generally used for treating tuberculosis, jaundice, fevers and bronchitis. It is also used in rat bite, cancerous ulcers and myalgia. It is administered to patients along with Karpooraadi chooranam or honey or betel leaf juice. The prescribed dose is 0.1-0.2 g. Particle size analysis by DLS showed presence of $10 \%$ of the particles below $139.9 \mathrm{~nm}$. TEM showed particles slightly larger than Linga Chenduram. EDAX showed the presence of $\mathrm{Hg}, \mathrm{S}, \mathrm{O}_{2}$ and small percentage $\mathrm{Au}$. $\mathrm{XRD}$ confirmed the presence of $\mathrm{HgS}$ as the main constituent. PCC did not show any characteristic peak in IR Spectroscopy and was similar to LC. $\mathrm{HgS}$ has been used for thousands of years in traditional medicines. Gold and its compounds have been used historically in drugs for treating wide variety of ailments. Nanosized gold particles proved to be effective in ameliorating the symptoms of mycobacterial-, collagen- and pristane- induced arthritis in rat models. Gold in the traditional Indian Ayurvedic medicine, Swarna bhasma (gold ash), has been characterized as globular particles of gold with an average size of $56-57 \mathrm{~nm}^{[6]}$. The form of the gold here in PCC could not be concluded.

$\mathrm{KsKc}$ is used to treat all diseases of the respiratory system including tuberculosis. It is generally administered to patients along with honey and Thirikadugu chooranam and is usually prescribed for 10 days. It has larger size compared to other Chendurams. EDAX and ICP showed the presence of mixture of many elements viz. $\mathrm{As}, \mathrm{Ca}, \mathrm{Fe}, \mathrm{Pb}$ and a small percentage of Au. Arsenic sulphide and Arsenic trioxide have long been used in traditional medicines for various diseases, yet arsenic can be highly toxic and carcinogenic. Inorganic arsenic is now accepted in Western medicine as a chemotherapeutic agent against certain hematopoietic cancers. Orpiment $\left(\mathrm{As}_{2} \mathrm{~S}_{3}\right)$ and Realgar $\left(\mathrm{As}_{4} \mathrm{~S}_{4}\right)$ are used externally for various skin diseases. Realgar is frequently included as an ingredient in oral traditional remedies for its antipyretic, antiinflammatory, antiulcer, anti-convulsive and antischistosomiasis actions. Total arsenic content alone should not be considered for safety evaluation and the form in which it is present is important. The form of As and $\mathrm{Au}$ here in KsKc could not be concluded. XRD and IR Spectra showed the presence of $\mathrm{Fe}_{3} \mathrm{O}_{4}$ as one of the components. Chronic administration of Swarnabhasma (which contains gold, lead and arsenic) showed no sign and symptom of liver and kidney toxicity in experimental animal model. Chronic Swarnabhasmatreated animals showed significantly increased superoxide dismutase and catalase activity, two enzymes that reduce free radical concentrations in the body. These antioxidant properties may have some important role in the rejuvenation of health ${ }^{[11]}$.

SP is used to treat cough, tuberculosis, piles, leucorrhoea, gonorrhoea and spermatorrhoea. It is given in the dose of $100 \mathrm{mg}$ twice a day with butter. The patients are advised to avoid tamarind and tobacco during treatment. It has $10 \%$ of the particles below $188.7 \mathrm{~nm}$. EDAX showed the presence of $\mathrm{Ag}$ and $\mathrm{O}_{2}$ but the exact form in which $\mathrm{Ag}$ is present could not be identified by XRD and IR data. Silver is known to possess strong antimicrobial properties both in its metallic and nanoparticle forms. The $\mathrm{Fe}_{3} \mathrm{O}_{4}$ attached $\mathrm{Ag}$ nanoparticles can be used for the treatment of water. Silver sulfadiazine provides better healing of burn wounds. The silver nanoparticles are reported to show better wound healing capacity, cosmetic appearance and scarless healing when tested using animal model. The microorganisms are unlikely to develop resistance against silver as compared to antibiotics as silver attacks a broad range of targets in the microbes ${ }^{[12]}$.

$\mathrm{NC}$ is used to treat ascities, piles, skin diseases, leprosy and white discharge. It is given in the dose of $100-200 \mathrm{mg}$. with three pungents powder in honey or ghee. NP is used to treat piles, fistula, diarrhea, cough, asthma and dysentery. It is administered along with butter or ghee or Thethan kottai lehyam in the dose of $100-200 \mathrm{mg}$ twice a day. NC has $10 \%$ of the particles below $357.8 \mathrm{~nm}$ and NP has $10 \%$ of the particles below $233.9 \mathrm{~nm}$. NP had overall less particulate size than NC. XRD confirmed the presence of $\mathrm{ZnO}$ in both. $\mathrm{ZnO}$ nanoparticles are proved to be effective against both Gram-positive and Gram-negative bacteria. They have antibacterial activity against even high-temperature resistant and high-pressure resistant spores. There appears to be an interaction between the bacterial cells and the $\mathrm{ZnO}$ particles, which is presumably due to the electrostatic forces ${ }^{[13]}$.

\section{CONCLUSION}

Among the metal based herbal medicines studied here, Linga Chenduram is found to have more number 
of particles in the nano range. TEM also confirmed the nano particles. They are generally taken with the adjuvants such as butter, ghee or honey. This can lead to better bio-absorption of some of these medicines. EDAX can be used to find the elemental composition at the surface level to identify the possible chemical form, but ICP-OES is a fully adequate technique for the multielemental determination of metals in Bhasmas. EDAX revealed that the medicines had metal mainly in oxide or sulphide form. XRD, IR and TGA analysis can be used as a physico-chemical fingerprint. These fingerprints could explain both the similarities and differences between various samples successfully and is a valuable primary tool for checking the quality control of metal-based medicines. Modern techniques are necessary to standardize and bring out high quality herbal products owing to their complex nature.

\section{ACKNOWLEDGEMENT}

The researchers would like to thank Rural Technology Action Group (RuTAG cell), IITM for financial support,Prof. M. Raveendran, RuTAG and Mr. S. Gopalakrishnan, RuTAG, for their constant support and encouragement, Dr. B.S.Murty, Department of Metallurgy, IITM for his help with XRD, Mr. Pavankumar Mantravadi and Dr.Ujjeevanam for their useful suggestions and SAIF, IIT Madras for analysis.

\section{REFERENCES}

1. Subbarayappa, B.V., 1997. Siddha medicine: An overview. Lancet, 350: 1841-1844. http://www.ncbi.nlm.nih.gov/pubmed/9428267

2. Joseph Thas, J., 2008. Siddha Medicinebackground and principles and the application for skin diseases. Clin. Dermatol., 26: 62-78. http://www.ncbi.nlm.nih.gov/pubmed/18280906

3. Marrero, J., G. Polla, R.J. Rebagliati, R. Pla, D. Gomez and P. Smichowski, 2007. Characterization and determination of 28 elements in fly ashes collected in a thermal power plant in Argentina using different instrumental techniques. Spectrochim. Acta Part B., 62: 101-108. http://cat.inist.fr/?aModele=afficheN\&cpsidt=18684854

4. Wadekar, M.P., C.V. Rode, Y.N. Bendale, K.R. Patil, A.B. Gaikwad and A.A. Prabhune, 2006. Effect of calcination cycles on the preparation of tin oxide based traditional drug: Studies on its formation and characterization. J. Pharm. Biomed. Anal., 41: 1473-1478.

http://cat.inist.fr/?aModele $=$ afficheN\&cpsidt $=1785$ 0713
5. Arvelakis, S. and F.J. Frandsen, 2005. Study on analysis and characterization methods for ash material from incineration plants. Fuel, 84: 1725-1738. http://cat.inist.fr/?aModele $=$ afficheN\&cpsidt $=1695$ 5817

6. Brown, C.L., G. Bushell, M.W. Whitehouse, D.S. Agrawal, S.G. Tupe, K.M. Paknikar and E.R.T. Tiekink, 2007. Gold 2006 presentation nanogold-pharmaceutics. Gold Bull., 40: 245-250. http://www.goldbulletin.org/assets/file/goldbulletin /downloads/tiekink_3_40.pdf

7. Ma, H.L., X.R. Qi, Y. Maitani and T. Nagai, 2007. Preparation and characterization of superparamagnetic iron oxide nanoparticles stabilized by alginate. J. Pharmaceut., 333: 177-186. http://cat.inist.fr/?aModele $=$ afficheN\&cpsidt $=1858$ 5149

8. Predoi, D., 2007. A study on iron oxide nanoparticles coated with dextrin obtained by co precipitation. Digest J. Nanomater. Biostruct., 2: $169-173$.

http://cat.inist.fr/?aModele $=$ afficheN\&cpsidt $=2020$ 6181

9. Hardy, A.D., H.H. Sutherland, R. Vaishnav and M.A. Worthing, 1995. A report on the composition of mercurials used in traditional medicines in Oman. J. Ethnopharmacol., 49: 17-22. http://cat.inist.fr/?aModele $=$ afficheN\&cpsidt $=2943$ 657

10. Chuu, J.J., C.J. Hsu and S.Y. Lin-Shiau, 2001. Abnormal auditory brainstem responses for mice treated with mercurial compounds: Involvement of excessive nitric oxide. Toxicology, 162: 11-22. http://www.ncbi.nlm.nih.gov/pubmed/11311454

11. Mitra, A., S. Chakraborty, B. Auddy, P. Tripathi, S. Sen, A.V. Saha and B. Mukherjee, 2002. Evaluation of chemical constituents and freeradical scavenging activity of Swarnabhasma (gold ash), an ayurvedic drug. J. Ethnopharmacol., 80: $147-153$.

http://www.ncbi.nlm.nih.gov/sites/entrez?Db=pub med $\&$ Cmd $=$ ShowDetailView $\&$ TermToSearch $=12$ 007704

12. Rai, M., A. Yadav and A. Gade, 2009. Silver nanoparticles as a new generation of antimicrobials. Biotech. Adv., 27: 76-83. http://www.ncbi.nlm.nih.gov/pubmed/18854209

13. Zhang, L. and Y. Ding, M. Povey and D. York, 2008. ZnO nanofluids-A potential antibacterial agent. Prog. Nat. Sci., 18: 939-944. http://d.wanfangdata.com.cn/Periodical_zrkxjze200808005.aspx 